\title{
Aerobic Nitric Oxide Production by Azospirillum brasilense Sp245 and Its Influence on Root Architecture in Tomato
}

\author{
Celeste Molina-Favero, ${ }^{1}$ Cecilia Mónica Creus, ${ }^{1}$ Marcela Simontacchi, ${ }^{2}$ Susana Puntarulo, ${ }^{2}$ and \\ Lorenzo Lamattina ${ }^{3}$ \\ ${ }^{1}$ Área Biomolecular, Unidad Integrada Balcarce, Instituto Nacional de Tecnología Agropecuaria-Universidad Nacional \\ de Mar del Plata. Km 73,5 Ruta 226 (7620) Balcarce, Argentina; ${ }^{2}$ Fisicoquímica PRALIB, Facultad de Farmacia \\ y Bioquímica, Universidad de Buenos Aires. Junín 965 (C1113AAD) Ciudad de Buenos Aires, Argentina; ${ }^{3}$ nstituto \\ de Investigaciones Biológicas, Facultad de Ciencias Exactas y Naturales, Universidad Nacional de Mar del Plata. CC 1245, \\ (7600) Mar del Plata, Argentina
}

Submitted 25 November 2007. Accepted 18 March 2008.

\begin{abstract}
The major feature of the plant-growth-promoting bacteria Azospirillum brasilense is its ability to modify plant root architecture. In plants, nitric oxide (NO) mediates indole3-acetic acid (IAA)-signaling pathways leading to both lateral (LR) and adventitious (AR) root formation. Here, we analyzed aerobic NO production by $A$. brasilense Sp245 wild type (wt) and its mutants Faj009 (IAA-attenuated) and Faj164 (periplasmic nitrate reductase negative), and its correlation with tomato root-growth-promoting effects. The wt and Faj009 strains produced 120 nmol NO per gram of bacteria in aerated nitrate-containing medium. In contrast, Faj164 produced 5.6 nmol NO per gram of bacteria, indicating that aerobic denitrification could be considered an important source of NO. Inoculation of tomato (Solanum lycopersicum Mill.) seedlings with both wt and Faj009 induced LR and AR development. In contrast, Faj164 mutant was not able to promote $L R$ or AR when seedlings grew in nitrate. When NO was removed with the NO scavenger 2-(4-carboxyphenyl)-4,4,5,5,-tetramethylimidazoline-1-oxyl-3-oxide (cPTIO), both LR and AR formation were inhibited, providing evidence that NO mediated Azospirillum-induced root branching. These results show that aerobic NO synthesis in $A$. brasilense could be achieved by different pathways and give evidence for an NO-dependent promoting activity on tomato root branching regardless of bacterial capacity for IAA synthesis.
\end{abstract}

Additional keywords: heterotrophic nitrification, lateral root, PGPB.

The rhizosphere is the place where a fundamental "conversation" between plant and microorganism occurs. Root activity alters the habitat of microorganisms and these, in turn, affect plant development, nutrition, and health. Azospirillum brasilense is a very promising bacterium among the group of plantgrowth-promoting bacteria (PGPB) (Bashan et al. 2004). Promoting effects on plants include-depending on environmental conditions-enhanced water status (Casanovas et al. 2003; Creus et al. 2004), increased nitrogen and mineral content

Corresponding author: Lorenzo Lamattina; Telephone: +54-223-4753030; Fax: +54-223-4753150; E-mail: lolama@mdp.edu.ar
(Bashan et al. 1990; Saudibet et al. 2002), and, eventually, an increase in crop yield (Okon and Labandera-González 1994).

A major feature of $A$. brasilense is its ability to produce changes in plant root architecture. Inoculation can promote development of lateral (LR) and adventitious (AR) roots (Creus et al. 2005; Fallik et al. 1994) and root hairs (Hadas and Okon 1987; Okon and Kapulnik 1986) in several plant species, thereby increasing root system. Reports attribute these effects to several possible mechanisms which include, among others, an increase in plant nutrient availability (Cohen et al. 1980; Okon and Kapulnik 1986), modification of plant cell membranes (Bashan et al. 1992), and production or modification of phytohormones (Bashan et al. 2004; Cassán et al. 2001), with the latter being the most common explanation. In addition, Bashan and Levanony (1990) postulated the "additive hypothesis," which ascribes the growth promotion to the result of multiple mechanisms working together.

Among the plant growth regulators produced by A. brasilense (Tien et al. 1979; Zakharova et al. 1999), indole-3-acetic acid (IAA) has been proposed to play a major role (Dobbelaere et al. 2003; Spaepen et al. 2007). The effect of Azospirillum inoculation on root elongation of wheat plants (Dobbelaerae et al. 1999; Kolb and Martin 1985) and on branching of wheat root hairs (Jain and Patriquin 1985) was mimicked by the application of IAA to roots; however, in some instances, the application of synthetic hormone did not simulated the effects induced by the bacterium (Yahalom et al. 1990). In A. brasilense, it has been also proposed that nitrite $\left(\mathrm{NO}_{2}^{-}\right)$could be implicated in root growth promotion (Zimmer et al. 1988). Nitrite is produced under anaerobic or microaerobic conditions by the dissimilatory nitrate reduction pathway in addition to nitric oxide (NO) and nitrous oxide $\left(\mathrm{N}_{2} \mathrm{O}\right)$ (Hartmann and Zimmer 1994). More recently, Creus and associates (2005) have reported that NO is involved in the LR formation in tomato induced by $A$. brasilense.

NO is a lipophilic and volatile free radical which participates in several processes, including metabolic, signaling, defense, and developmental pathways in plants (Lamattina and Polacco 2007; Lamattina et al. 2003). There is an extensive linkage between NO and classical plant hormones (Beligni and Lamattina 2001). For instance, Gouvêa and associates (1997) showed that NO donors such as sodium nitroprusside and nitrosoglutathione can induce growth elongation in maize root segments, proposing that $\mathrm{NO}$ could be an intermediary in the 
IAA-induced root elongation. Thereafter, it has been demonstrated that $\mathrm{NO}$ is produced and required as a downstream component in the auxin-induced signaling pathways leading to AR development in cucumber (Pagnussat et al. 2002, 2003) and LR formation in tomato (Correa-Aragunde et al. 2004).

NO can be produced by several pathways in bacteria growing under aerobic conditions (Molina-Favero et al. 2007). i) Aerobic denitrification: in addition to anaerobic denitrification, it now has been accepted that denitrification can occur under fully aerobic conditions. This process is not accomplished by the classical membrane-bound respiratory nitrate reductase (Nar) but by a periplasmic nitrate reductase (Nap) (Jetten et al. 1997). In A. brasilense Sp245, Steenhoudt and associates (2001a) have identified a Nap which is neither repressed nor inactivated by oxygen. ii) Heterotrophic nitrification: through this pathway, ammonium is oxidized sequentially to hydroxylamine $\left(\mathrm{NH}_{2} \mathrm{OH}\right), \mathrm{NO}_{2}{ }^{-}$and $\mathrm{NO}_{3}{ }^{-}$, with $\mathrm{NO}$ being generated as an intermediary in the reduction of $\mathrm{NO}_{2}^{-}$to $\mathrm{N}_{2}$ (Wrage et al. 2001). iii) NO synthase (NOS): the activity of this enzyme can also produce NO aerobically by oxidizing arginine, in the presence of $\mathrm{O}_{2}$, to L-citrulline and NO (Stuerh 1997). Recently, the presence of an nirK gene in A. brasilense Sp245 encoding a NO-producing nitrite reductase copper-containing enzyme type was reported (Pothier et al. 2007). These authors also

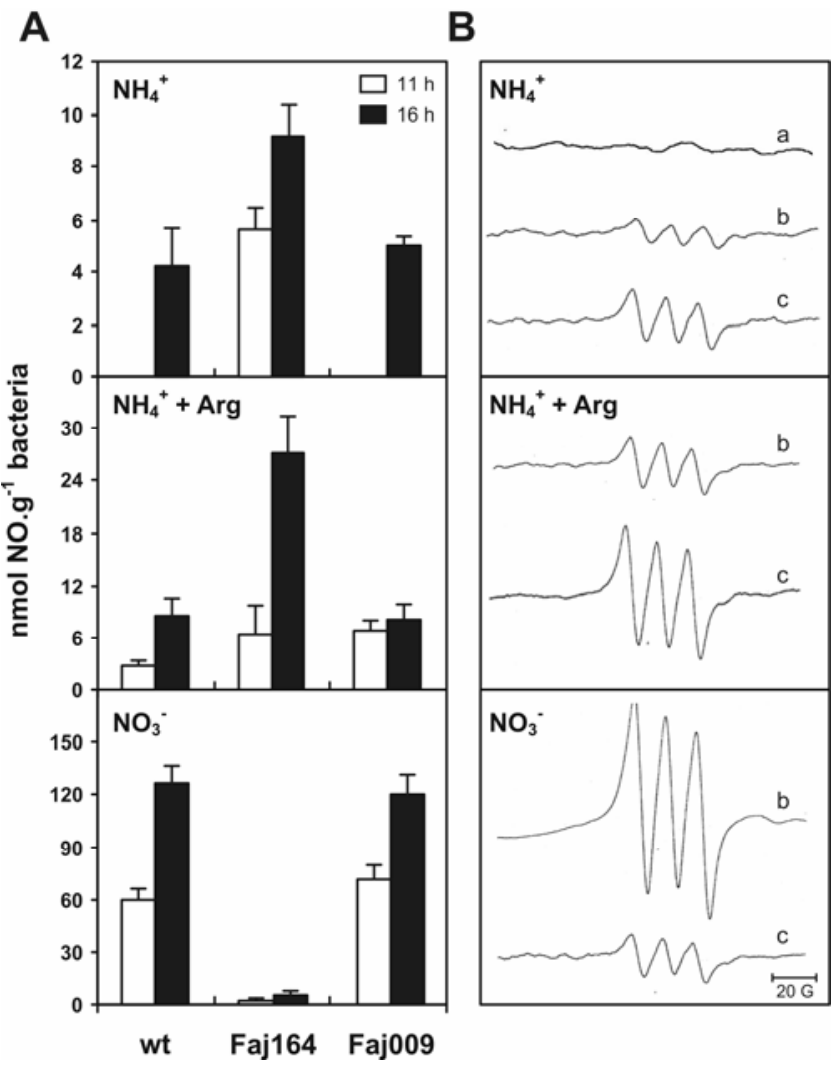

Fig. 1. Aerobic nitric oxide (NO) production by Azospirillum brasilense Sp245 wild type (wt), the periplasmic nitrate reductase-negative $\left(\mathrm{Nap}^{-}\right)$ mutant Faj164, and the indole-3-acetic acid-attenuated mutant Faj009. A, Endogenous NO levels were quantified by electron paramagnetic resonance (EPR) in pellets (approximately $0.2 \mathrm{~g}$ ) of $A$. brasilense wt, Faj164, and Faj009. Bacteria were grown for $11 \mathrm{~h}$ (middle of log phase) or $16 \mathrm{~h}$ (end of log phase) in aerated liquid OAB medium (Okon et al. 1977) with ammonium $\left(\mathrm{NH}_{4}{ }^{+}\right), \mathrm{NH}_{4}{ }^{+}$supplemented with $15 \mathrm{mM}$ Arginine $\left(\mathrm{NH}_{4}{ }^{+}\right.$ + Arg), or nitrate $\left(\mathrm{NO}_{3}{ }^{-}\right)$. EPR quantifications were duplicated in pools of two (for $16 \mathrm{~h}$ ) or four (for $11 \mathrm{~h}$ ) cultures. B, EPR spectra of pellets of $A$. brasilense wt (b) and Faj164 (c) grown for $16 \mathrm{~h}$ as indicated above. EPR spectra were also performed with bacteria boiled for $5 \mathrm{~min}$ (a). The area above the baseline indicates the amount of NO for each pellet. EPR spectrum of wt grown in nitrate was divided by two for scaling. showed that nirK expression is induced by wheat seed or root extracts (Pothier et al. 2007). Because it was reported that NO can be produced by $A$. brasilense $\mathrm{Sp} 245$ under oxic conditions (Creus et al. 2005), and considering that an aerobic environment can be encountered in the rhizosphere, it is important to characterize the aerobic NO production by this bacterium. The use of a mutant devoid of its Nap activity seems to be a good strategy for this purpose. In this work, we report the NO production by A. brasilense Sp245 wild type (wt) and its isogenic mutants Faj164 (Nap ${ }^{-}$) (Steenhoudt et al. 2001a) and Faj009 (IAA-attenuated) (Dobbelaere et al. 1999), growing under different $\mathrm{N}$-available sources. In addition, the NO production is correlated to the ability of $A$. brasilense to promote LR and AR development in tomato. Finally, the link between NO and IAA in A. brasilense-induced tomato root growth is explored.

\section{RESULTS}

\section{Growth and NO production by A. brasilense wt, Faj009, and Faj164 strains.}

NO production under aerobic growth conditions was investigated in $A$. brasilense $\mathrm{Sp} 245 \mathrm{wt}$ and its isogenic mutants Faj009, negative for indole-3-pyruvate decarboxylase and with a 90\% reduction in IAA synthesis (Costacurta et al. 1994; Dobbelaere et al. 1999) and Faj164, negative for the periplasmic nitrate reductase (Steenhoudt et al. 2001a). Bacteria were grown for 11 or $16 \mathrm{~h}$, corresponding to middle and end of $\log$ phase of growth, respectively, and NO was quantified by electron paramagnetic resonance (EPR). NO was produced in cultures with $\mathrm{NO}_{3}^{-}, \mathrm{NH}_{4}^{+}$, or $\mathrm{NH}_{4}^{+}$plus arginine (Fig. 1). The concentrations were higher at the end of log phase in all strains (Fig. 1A). NO was not detected when pellets were previously boiled (Fig. 1B), confirming that NO was produced only by living bacteria. The three-line EPR spectra, characteristic of the [(MGD) $)_{2} / \mathrm{Fe}-\mathrm{NO}$ ] complex (Komarov and Lai 1995), for wt and the Faj164 mutant grown for $16 \mathrm{~h}$ in the different media is shown in Figure 1B.

In order to determine whether A. brasilense is able to produce NO by aerobic denitrification, we grew microorganisms in aerated nitrate-containing OAB medium (Okon et al. 1977). A production of approximately $120 \mathrm{nmol}$ NO per gram of bacteria was obtained for both the wt and the IAA-attenuated strains (Fig. 1A). The NO concentration was approximately 25-fold higher in $\mathrm{NO}_{3}^{-}$- than in $\mathrm{NH}_{4}^{+}$-grown A. brasilense, except for the Nap mutant Faj164, which produced merely 5.6 nmol NO per gram of bacteria (Fig. 1A and B).

In agreement with previous results (Creus et al. 2005), A. brasilense wt produced approximately $4.2 \mathrm{nmol} \mathrm{NO}$ per gram of bacteria when grown in ammonium (Fig. 1A). Comparable values were obtained for the IAA-attenuated mutant Faj009 (Fig. 1A). The possibility that NO can be produced by NOSlike activity was evaluated growing bacteria with arginine. In the three strains, arginine induced an earlier, because it was observed also at $11 \mathrm{~h}$, and higher production of NO than that produced when bacteria were grown in $\mathrm{NH}_{4}{ }^{+}$alone (Fig. 1A). Interestingly, the Faj164 mutant displayed an increased NO production when growing in ammonium with or without arginine (Fig. 1A and B).

The synthesis of NO was further studied by fluorometric analysis with the NO-specific fluorescent probe 4,5-diaminofluorescein diacetate (DAF-2DA). The relative NO production of cultures of the three strains of Azospirillum in the different media after $2 \mathrm{~h}$ of incubation with the probe is shown in Figure 2. These results were in agreement with those obtained by EPR.

Another pathway which could be operating in Azospirillum spp. to produce NO in aerobic condition is the heterotrophic nitrification. This possibility was tested fluorometrically by 
incubating $\left(\mathrm{NH}_{4}^{+}\right) \mathrm{OAB}$-grown bacteria with hydroxylamine and DAF-2DA, as described above. An increased NO signal could be observed when bacteria were incubated in the presence of hydroxylamine (Fig. 3). The kinetics of NO production were the same for both wt and Faj164, with a NO maximal slope of 0.235 arbitrary units (AU) $\mathrm{min}^{-1}$ maintained for approximately $32 \mathrm{~min}$. The maximal rate of NO production was 4 times higher in the presence of hydroxylamine, with $\mathrm{NO}$ being produced 1.5 times higher after $2 \mathrm{~h}$ (Fig. 3). Results for the Faj009 mutant were similar to wt (data not shown).

To rule out the possibility that differences in NO production could be ascribed to unequal bacterial growth in the different $\mathrm{N}$-sources media, we studied growth parameters. The growth kinetics were not significantly different between wt, Faj164 (Fig. 4), and Faj009 (not shown) in all media. Exponential growth was kept for approximately $11 \mathrm{~h}$ (average), with specific growth rates $(\mu)$ ranging from 0.38 to $0.46 \mathrm{~h}^{-1}$ (taken from the optical density at $540 \mathrm{~nm}$ curves). The stationary phase was reached between 16 and $18 \mathrm{~h}$ of growth (Fig. 4). Slightly lower $m$ values were obtained in $\mathrm{NO}_{3}^{-}$than in $\mathrm{NH}_{4}{ }^{+}$or

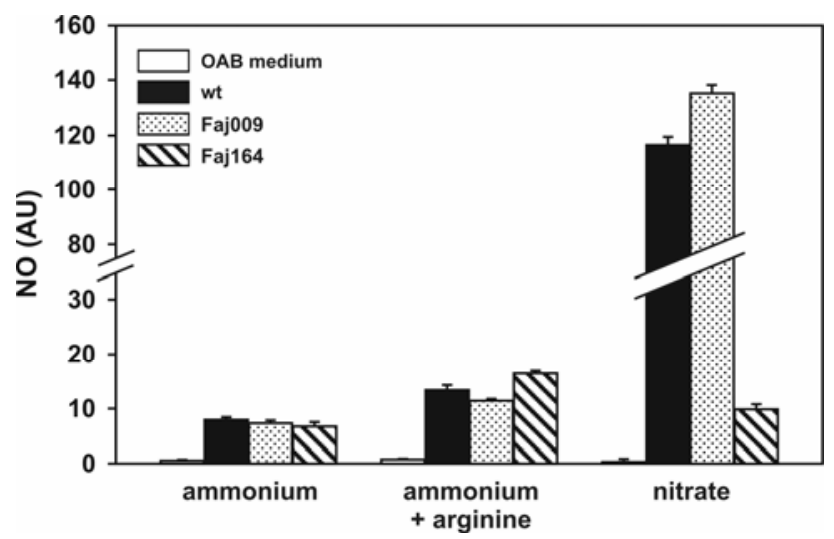

Fig. 2. Fluorometric determination of aerobic nitric oxide (NO) production by Azospirillum brasilense $\mathrm{Sp} 245$ wild type (wt), the periplasmic nitrate reductase-negative $\left(\mathrm{Nap}^{-}\right)$mutant Faj164, and the indole-3-acetic acidattenuated mutant Faj009. Cultures $(100 \mu \mathrm{l})$ of A. brasilense wt, Faj164, and Faj009 grown for $16 \mathrm{~h}$ in aerated OAB medium (Okon et al. 1977) containing ammonium, ammonium plus arginine, or nitrate as $\mathrm{N}$ source were incubated in a 96-well plate with $10 \mu \mathrm{M}$ of the NO-specific fluorescent probe 4,5-diamino-fluorescein diacetate. Fluorescence intensity was measured with a Fluoroskan Ascent microplate reader (Labsystems, 480$\mathrm{nm}$ excitation, 525-nm emission) after $2 \mathrm{~h}$ of incubation. Controls were done with noninoculated liquid medium $(\mathrm{OAB})$. Values are means \pm standard error of three measurements. AU: arbitrary units. in $\mathrm{NH}_{4}{ }^{+}$supplemented with arginine (Fig. 4). The growth of Faj164 strain with nitrate as $\mathrm{N}$-source was as expected because this mutant still has the assimilatory nitrate reductase activity (Steenhoudt et al. 2001a). When the cell number was analyzed, no significant differences were obtained for the different treatments. Average most probable number $(\mathrm{MPN}) \mathrm{ml}^{-1}$ ( \pm standard deviation) was $9.6 \times 10^{7}\left( \pm 3 \times 10^{7}\right)$ and $5.7 \times 10^{11}\left( \pm 3 \times 10^{11}\right)$ at the middle $(11 \mathrm{~h})$ and the end $(16 \mathrm{~h})$ of $\log$ phase, respectively, for all strains.

\section{A. brasilense-induced LR and AR requires NO production.}

Considering the role of both IAA and NO in the regulation of root development (Casimiro et al. 2003; Correa-Aragunde et al. 2004) and the capability of A. brasilense to produce the two compounds, we next analyzed LR and AR formation in tomato seedlings inoculated with the different strains and the requirement of NO in this process. For this study, it was necessary to remove NO; therefore, we first evaluated the effect of the specific NO scavenger 2-(4-carboxyphenyl)-4,4,5,5,-tetrame-

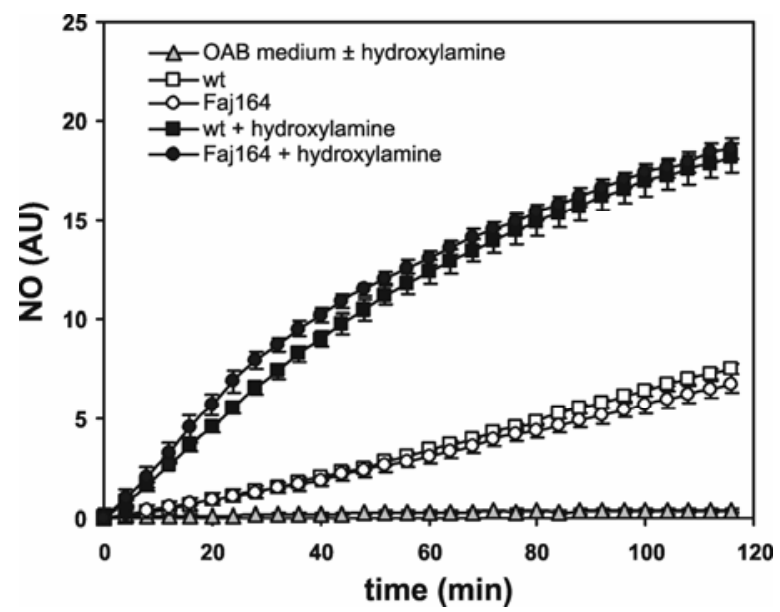

Fig. 3. Aerobic nitric oxide (NO) production by Azospirillum brasilense Sp245 wild type (wt) and the $\mathrm{Nap}^{-}$mutant Faj164 in the presence of hydroxylamine. Cultures $(100 \mu \mathrm{l})$ of A. brasilense wt and Faj164 grown for $16 \mathrm{~h}$ in aerated OAB medium (Okon et al. 1977) were incubated in a 96well plate containing $10 \mu \mathrm{M}$ of the NO-specific fluorescent probe 4,5-diamino-fluorescein diacetate with or without $0.1 \mathrm{mM}$ hydroxylamine. Fluorescence intensity was measured with a Fluoroskan Ascent microplate reader (Labsystems, 480-nm excitation, 525-nm emission) every 4 min for $2 \mathrm{~h}$. Control kinetics were done with noninoculated OAB medium with or without $0.1 \mathrm{mM}$ hydroxylamine. Values are means \pm standard error of three measurements. AU: arbitrary units.

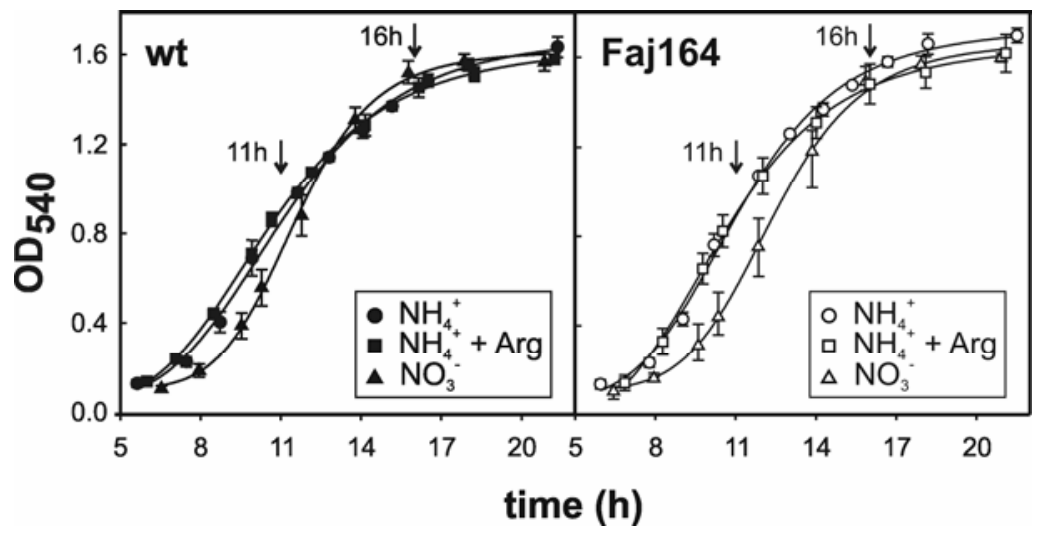

Fig. 4. Growth kinetics of Azospirillum brasilense Sp245 wild type (wt) and the Nap ${ }^{-}$mutant Faj164. A. brasilense wt (left) and Faj164 (right) were grown in aerated liquid medium with ammonium $\left(\mathrm{NH}_{4}{ }^{+}\right)$or nitrate $\left(\mathrm{NO}_{3}{ }^{+}\right)$as $\mathrm{N}$ source and in $\mathrm{NH}_{4}{ }^{+}$supplemented with $15 \mathrm{mM}$ arginine $\left(\mathrm{NH}_{4}{ }^{+}+\mathrm{Arg}\right)$. Cultures were done for $22 \mathrm{~h}$ at $32^{\circ} \mathrm{C}$ under agitation $(100 \mathrm{rpm})$. Optical density readings were performed at $540 \mathrm{~nm}\left(\mathrm{OD}_{540}\right)$. Values are means \pm standard error of three independent cultures for each treatment. Arrows indicates the middle $(11 \mathrm{~h})$ and the end $(16 \mathrm{~h})$ of $\log$ phase. 
thylimidazoline-1-oxyl-3-oxide (cPTIO) on bacteria growth. This was analyzed by a disk diffusion susceptibility test. As expected, a growth-inhibition zone was present around kanamycin-soaked and absent around OAB-soaked filter disks in both Luria-Bertani (LB) and agar congo red (ACR) media (Fig. 5). When filter disks were soaked in $1 \mathrm{mM}$ cPTIO, there were no inhibition zones around the disk, indicating that cPTIO does not interfere with the growth of A. brasilense (Fig. 5). The same results were observed for both Faj009 and Faj164 mutants (data not shown). For these strains, ethanol was used as inhibitor control, because both strains are kanamycin resistant.

When seedlings were incubated in sterile distilled water (SDW), inoculation with any strain increased LR number compared with noninoculated seedlings (Fig. 6A). This promotion was dependent on NO because the addition of cPTIO restored the LR values to the control noninoculated seedlings (Fig. 6A). The wt and Faj164 strains induced higher LR development than Faj009 strain (Fig. 6A) in agreement with previous findings in wheat inoculated with different Azospirillum-impaired IAA strains (Barbieri and Galli 1993; Dobbelaere et al. 1999).

Taking into account the significant NO levels produced by A. brasilense grown with nitrate as $\mathrm{N}$ source, we next analyzed the effects of inoculation on root development in seedlings growing in the presence of nitrate. It was reported that nitrate could induce an increase in LR number by itself (Zhang and Forde 2000). Our results also showed a threefold increase in LR number in noninoculated seedlings incubated with nitrate (Fig. 6B). Inoculation with wt or Faj009 in the presence of $\mathrm{NO}_{3}^{-}$has an additive effect on LR development (Fig. 6B). This
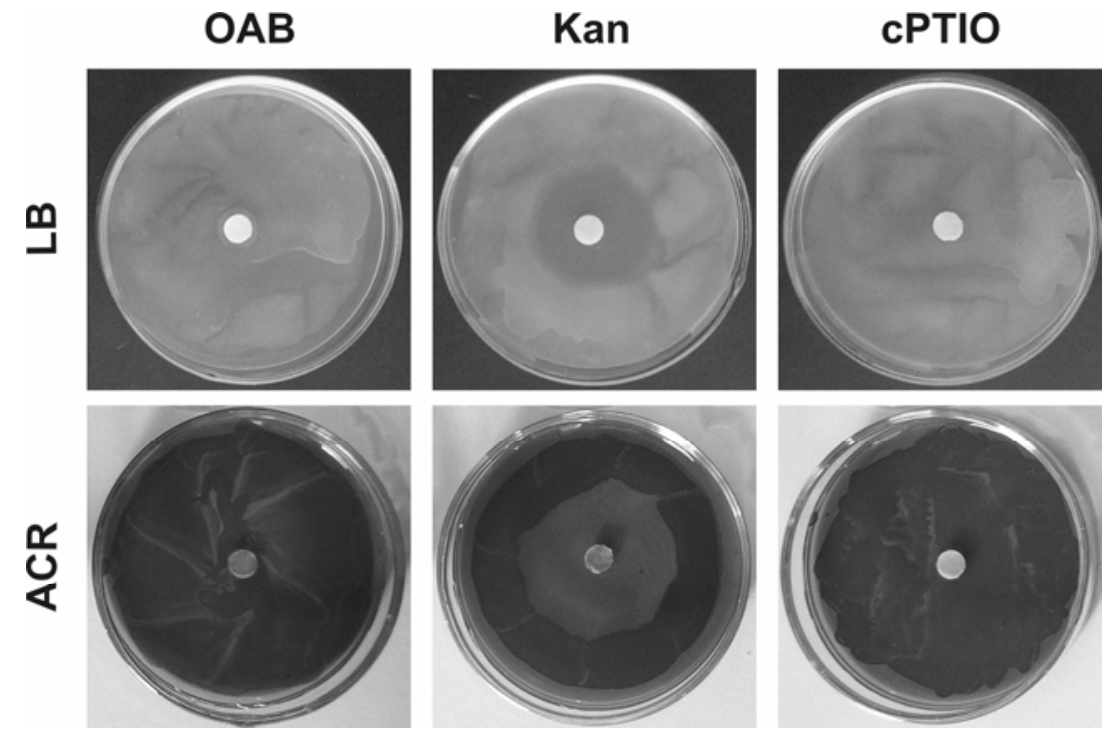

Fig. 5. NO scavenger 2-(4-carboxyphenyl)-4,4,5,5,-tetramethylimidazoline-1-oxyl-3-oxide (cPTIO) does not affect the growth of Azospirillum brasilense. A. brasilense wild type was grown overnight in liquid OAB medium (Okon et al. 1977), pelleted, resuspended in phosphate buffer, and plated on Luria Bertani (LB) agar or congo red agar (ACR). Filter disks imbibed in OAB medium (OAB), kanamycin at $25 \mu \mathrm{g} \mathrm{ml}^{-1}$ (Kan), or $1 \mathrm{mM} \mathrm{cPTIO}$ (cPTIO) were placed in the center of the bacteria lawn and plates incubated for $24 \mathrm{~h}$ (LB) or $48 \mathrm{~h}$ (ACR). Kanamycin and OAB medium were used as positive or negative control, respectively. The absence of a growth-inhibition zone around the filter disk was considered as indicative of no toxic effects.

A

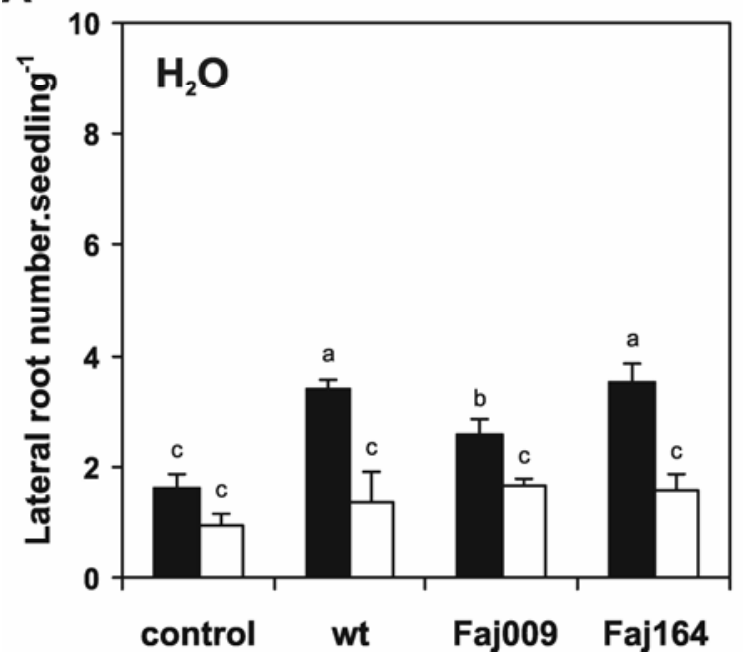

B

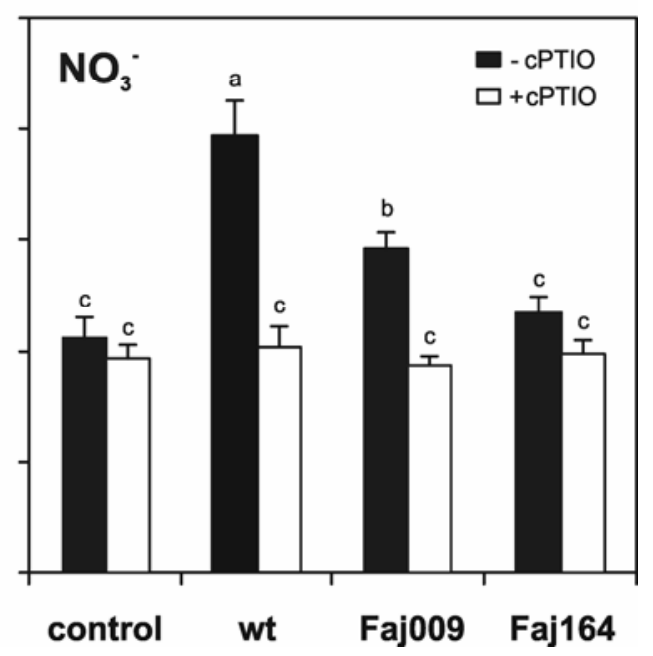

Fig. 6. Effects of inoculation with Azospirillum brasilense Sp245 wild type (wt), the indole-3-acetic acid-attenuated mutant Faj009, and the Nap ${ }^{-}$mutant Faj164 on lateral root formation. Tomato seeds were pregerminated and then inoculated with A. brasilense wt or Faj009 and Faj164 mutants (10 ${ }^{7}$ cells seed ${ }^{-1}$ ). Noninoculated seed (control) were imbibed in sterile distilled water (SDW). Seeds were then incubated in moistened filter paper imbibed in A, SDW or B, $10 \mathrm{mM} \mathrm{KNO}_{3}$ with or without $1 \mathrm{mM}$ of the $\mathrm{NO}$ scavenger 2-(4-carboxyphenyl)-4,4,5,5,-tetramethylimidazoline-1-oxyl-3-oxide (cPTIO). After 6 days, the number of lateral root per seedling was determined. Values are means \pm standard error of 3 to 12 independent replicates (with 10 seeds each) for each treatment. Different letters indicate significant difference at $P<0.05$ (Tukey's test). 
increase was largely dependent on NO because cPTIO treatment was able to restore the level of LR number to the noninoculated values (Fig. 6B). Moreover, the Nap mutant Faj164, which produced less than $5 \%$ of the wt NO level when it was grown in nitrate (Fig. 1), was not able to promote LR formation, with the LR number being not significantly different from the noninoculated control value (Fig. 6B). In both noninoculated and inoculated seedlings, cPTIO did not prevent the increase in LR number induced by nitrate (Fig. 6A and B). Similar results were observed when LR numbers were quantified in seedlings incubated with $5 \mathrm{mM}$ nitrate (data not shown).

NO also has an important role in the promotion of ARs by A. brasilense (Fig. 7). The percentage of plants displaying AR increased 10-fold in wt- or Faj009-inoculated seedlings compared with noninoculated ones when incubated in nitrate. The addition of cPTIO prevented this effect (Fig. 7). Again, this induction was not observed for the Nap-negative mutant. When incubations were done in SDW, neither inoculated nor noninoculated seedlings displayed AR (data not shown). It was proposed that nitrite produced by $A$. brasilense by denitrification could stimulate root growth (Zimmer et al. 1988); therefore, we tested this possibility by growing inoculated and noninoculated seedlings with $0.5 \mathrm{mM}$ potassium nitrite. After 6 days of treatment, no differences in LR or AR number were found between SDW and nitrite incubations for either noninoculated or inoculated seedlings (data not shown), indicating that, at least at this concentration, nitrite has no promoting effects on tomato root development. When the length of primary root was analyzed, no significant differences were obtained among all tested treatments (data not shown), pointing out that the observed promoting effect of A. brasilense was mainly at the branching level.

After incubations, roots were collected to evaluate root colonization by $A$. brasilense. As expected, noninoculated seedlings exhibited low values of bacterial number, being approximately $10^{3}$ - to $10^{4}$-fold lower than inoculated values. The synthesis of auxin at the level of the wt strain seemed not to be an important factor in the colonization process, because the same bacterial numbers were recovered in wt- or Faj009-inoculated roots, being approximately $3.6 \times 10^{8}\left( \pm 2.6 \times 10^{8}\right)$ MPN of bacteria $g^{-}$ ${ }^{1}$ of root dry weight (DW) in seedlings incubated in SDW. Slightly lower cell numbers were obtained for Faj164 in both nitrate or SDW incubations, being $2.1 \times 10^{8}\left( \pm 1.1 \times 10^{8}\right)$ and $1.6 \times 10^{8}\left( \pm 4.6 \times 10^{7}\right)$ MPN of bacteria $\mathrm{g}^{-1}$ of root DW in SDW and nitrate, respectively. In all treatments, the cell numbers were in the range of $10^{8} \mathrm{MPN}$ of bacteria $\mathrm{g}^{-1}$ root DW, indicating that colonization was effective for the three strains and that differences in root growth promotion were not due to differences in bacteria cell number.

\section{DISCUSSION}

NO production by denitrification in Azospirillum spp. has been accepted for a long time (Hartmann and Zimmer 1994). In contrast, aerobic NO production was recently reported by our group (Creus et al. 2005). In this condition, several pathways can be proposed for NO synthesis: i) by a NO synthase, which uses arginine as substrate, such as in animals (Stuehr 1997) and bacteria (e.g., Rhodococcus sp.) (Cohen and Yamasaki 2003); ii) by heterotrophic nitrification (Wrage et al. 2001); iii) by aerobic denitrification (Jetten et al. 1997) through an aerobically active respiratory Nap, which produces nitrite that, in turn, can be reduced to NO enzymatically (Hartmann and Zimmer 1994) or nonenzymatically in the presence of a reductant such as ascorbate (Beligni and Lamattina 2001); and iv) by an assimilatory nitrate reductase, which also produces $\mathrm{NO}_{2}^{-}$(Hartmann and
Zimmer 1994). We report here experimental evidence supporting the idea that at least two mechanisms are present in A. brasilense Sp245 for aerobic NO production, one in the presence of $\mathrm{NH}_{4}{ }^{+}$, unrelated to denitrification, and other in the presence of $\mathrm{NO}_{3}^{-}$(Figs. 1 and 2). None of these mechanisms seem to be related to IAA synthesis because no differences in NO production were observed between wt and Faj009 strains in all tested growth conditions (Fig. 1A). The four-times increase in the rate of NO production when the culture media was supplemented with hydroxylamine suggests that a heterotrophic nitrificationlike pathway is active in $A$. brasilense converting $\mathrm{NH}_{4}{ }^{+}$into $\mathrm{NO}$ (Fig. 3). The presence of a NOS-like activity is also suggested, because arginine induced an increase in NO level (Figs. 1 and 2). Several reports showed that, in plants, NO synthesis increases when incubated with arginine (Jasid et al. 2006). However, neither NOS gene nor protein have been conclusively identified in plants (Zemojtel et al. 2006), raising the hypothesis that arginine could be converted into NO by a different pathway. This possibility deserves to be studied in A. brasilense in order to be more conclusive. Interestingly, the bacterium produced significant amounts of NO by aerobic nitrate reduction. This is likely achieved through an aerobic denitrification pathway, because the Nap ${ }^{-}$mutant produced only $5 \%$ of NO compared with the wt strain (Figs. 1 and 2), with the remaining 5\% possibly being produced by nitrate assimilation. In agreement with these results, it has been stated that heterotrophic nitrifiers are frequently aerobic denitrifiers (Wrage et al. 2001). In the rhizosphere, the different NO-producing pathways could be accomplished alternatively or complementarily according to the nutrient present in the rhizosphere, making $A$. brasilense flexible to adapt their $\mathrm{N}$-metabolism to $\mathrm{NH}_{4}^{+}, \mathrm{NO}_{3}^{-}$, or arginine availability and, therefore, enhancing its ability for plant-growth-promoting effects. Regardless of the growth media, an increase in the NO synthesized was observed for all strains at the end of log phase (Fig. 1A). Such increase was likely due to the stress produced by the lack of nutrients and the presence of toxic metabolic products associated with the entry in the stationary phase.

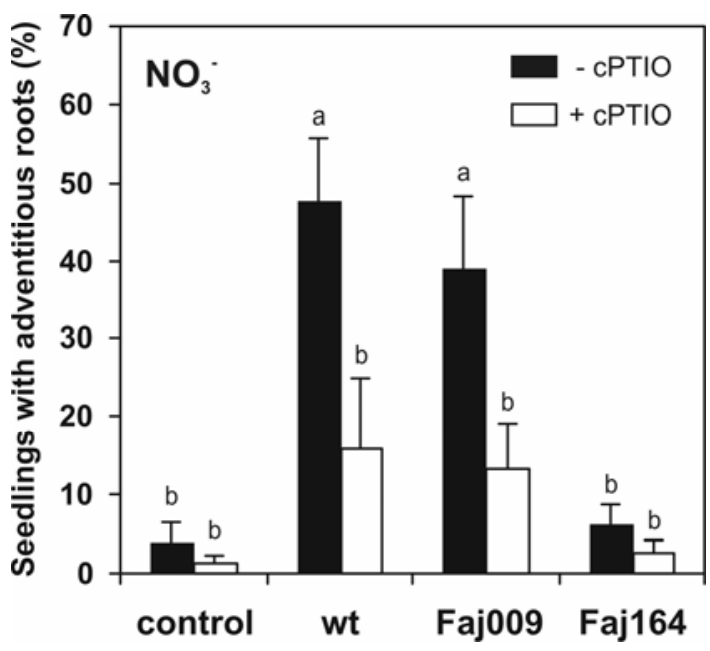

Fig. 7. Effects of inoculation with Azospirillum brasilense Sp245 wild type (wt), the indole-3-acetic acid-attenuated mutant Faj009, and the Nap ${ }^{-}$ mutant Faj164 on adventitious root formation. Tomato seeds were pregerminated and then inoculated with A. brasilense wt or Faj009 and Faj164 mutants $\left(10^{7}\right.$ cells seed $\left.{ }^{-1}\right)$. Noninoculated seeds (control) were imbibed in sterile distilled water (SDW). Seeds were then incubated in moistened filter paper imbibed in $10 \mathrm{mM} \mathrm{KNO}_{3}$ with or without $1 \mathrm{mM}$ of the NO scavenger 2-(4-carboxyphenyl)-4,4,5,5,-tetramethylimidazoline-1-oxyl-3-oxide (cPTIO). After 6 days, the percentage of plants displaying at least one adventitious root was calculated. Values are means \pm standard error of 3 to 12 independent replicates (with 10 seeds each) for each treatment. Different letters indicate significant difference at $P<0.05$ (Tukey's $t$ test). 
The ubiquitous stress-associated presence of NO has been reported in different organisms (Frey and Kallio 2003; Lamattina et al. 2003; Thippeswamy et al. 2006). In addition, similar behavior has been reported for IAA production, which is increased under carbon limitation and reduction in growth rate (Ona et al. 2005).

Generally, denitrification has been considered to be an undesirable feature of PGPB and symbiotic rhizobacteria for achieving plant growth promotion because it reduces the $\mathrm{N}$ availability (Daniel et al. 1980; Zimmer et al. 1984). In this work, we demonstrate that $A$. brasilense can reduce nitrate aerobically producing NO (Figs. 1 and 2), which in turn could promote tomato root growth (Figs. 6 and 7). These results are in agreement with previous works which have shown that Azospirillum mutants defective in $\mathrm{NO}_{3}^{-}$reduction are less competent than the wt strain in establishing plant-bacteria associations (Baldani et al. 1986, Steenhoudt et al. 2001b) and less effective in promoting plant growth (Boddey et al. 1986). In addition, Zimmer and associates (1988) have postulated that nitrite, produced by denitrification, could have promoting effects when reacting with ascorbate. Regarding NO chemistry, this observation can be explained by the nonenzymatic reduction of nitrite to $\mathrm{NO}$ by ascorbate at acidic $\mathrm{pH}$ (Weitzberg and Lundberg 1998). On the other hand, NO produced by denitrifiers may also affect competing bacteria such as Bacillus subtilis, by causing them stress and growth inhibition (Choi et al. 2006), and may also disrupt biofilm formed by neighboring bacteria (Barraud et al. 2006). Such effects could be making $A$. brasilense $\mathrm{Sp} 245$ more competitive in the rhizosphere, a characteristic that remains to be investigated.

The beneficial effects of PGPB on plant growth are correlated with changes in root architecture, mainly associated with the stimulation of root branching (Mantelin and Touraine 2004; Molina-Favero et al. 2007; Okon and Kapulnik 1986). It is generally accepted that these developmental responses are triggered by phytohormones produced by the bacterium. Among them, auxin is considered to play a major role. In A. brasilense, IAA biosynthesis is dependent on the presence of tryptophan (Zimmer and Bothe 1988) as well as on carbon limitation and a reduction in growth rate (Ona et al. 2005). In contrast to IAA, which seems to be produced only at late logarithmic or stationary growth phase (Ona et al. 2005), NO is produced during the middle (at $11 \mathrm{~h}$ ) and late logarithmic (at $16 \mathrm{~h}$ ) phases of growth, when nitrate or arginine are present (Fig. 1). This aerobic NO synthesis was shown to be well correlated to the LR and AR development induced by $A$. brasilense in tomato, because inoculation with the Nap ${ }^{-}$mutant Faj164 was not able to induce root growth in the presence of nitrate (Figs. 6 and 7). In addition, when seedlings were incubated in nitrate, less than $5 \%$ of noninoculated seedlings developed AR compared with 40 and $47 \%$ observed in wt- or Faj009-inoculated seedlings, respectively (Fig. 7). One possible explanation is that, even in the presence of nitrate, the NO levels produced by 6-day-old tomato seedlings were suboptimal to trigger AR development, and threshold NO concentration for this response was achieved only with bacterial inoculation. Finally, when NO was removed with cPTIO, the LR and AR development induced by the bacterium were shut down to the noninoculated values (Figs. 6 and 7), strengthening the idea that NO is critical as a signaling or effector molecule for the observed stimulatory effects. Nevertheless, it cannot be discarded that $A$. brasilense could also trigger NO formation by the root which, in turn, may lead to an enhanced root branching process.

In inoculation experiments, several authors have shown evidence of a lack of correlation between the capacity for IAA synthesis of A. brasilense and the effects on root growth promotion (Bothe et al. 1992; Harari et al. 1989; Kapulnik et al.
1985). In addition, several studies showed that AzospirillumIAA biosynthesis alone cannot account for the overall plant growth stimulatory effect observed (Spaepen et al. 2007). In this work, we report results demonstrating that the IAA-attenuated mutant Faj009 of A. brasilense, which produces only up to $10 \%$ of the IAA level compared with the wt strain (Dobbelaere et al. 1999), still promotes LR and AR formation in tomato seedlings. This promotion could be ascribed to NO, because cPTIO shut down the induced LR and AR development to the noninoculated values (Figs. 6 and 7). Some differences were observed in the effects of the wt and the auxin-attenuated mutant, indicating that IAA synthesis is responsible for part of the promoting effect. These results are consistent with previous experiments in tomato using the auxin competitive inhibitor $\alpha$ ( $p$-chlorophenoxy) isobutyric acid (Creus et al. 2005). Nevertheless, the presence of cPTIO in the culture medium reduced LR and AR promotion to the same level for both strains, suggesting that NO could also mediate the promoting effects of the IAA produced by A. brasilense. The role of NO as a second messenger in auxin-induced growth processes in roots has been established during recent years. A transient NO biosynthesis has been observed in treatments of cucumber and tomato roots with exogenously added auxin, with this production being required for AR formation (Pagnussat et al. 2002, 2003) and LR development (Correa-Aragunde et al. 2004). We do not know yet if the effects induced by inoculation involve the action of NO, directly or indirectly in plants other than tomato. Nevertheless, it seems likely because the role of NO in root development has been further confirmed in Arabidopsis, lettuce, mung bean, mountain ginseng, and rapeseed, for instance (Cao et al. 2007; Huang et al. 2007; Lombardo et al. 2006; Tewari et al. 2007). The way by which IAA and NO are acting on plant cells triggering the branching of roots is not clear. Very recent data demonstrate that NO is active in regulating cell cycle programs through induction of cyclin D3 in tomato roots (CorreaAragunde et al. 2006) and also in the induction of cell division in alfalfa cell cultures (Ötvös et al. 2005). The possibility that these effects could be triggered by Azospirillum NO produced in the interaction of bacteria with roots is open.

Overall, in this work, the existence of an NO-dependent promoting activity in A. brasilense Sp245 which induces morphological changes in tomato roots regardless of the full bacterial capacity for IAA synthesis was demonstrated. Furthermore, new insights which correlate the aerobic NO-producing activity present in $A$. brasilense in different $\mathrm{N}$ sources with tomato root growth promotion are reported. Finally, in addition to the well-established connection between NO production and plant defense responses to pathogen microorganisms (Modolo et al. 2005; Zeidler et al. 2004), it seems that NO metabolism itself also plays a relevant role in the intimate association of plantgrowth-promoting rhizobacteria with roots to benefit crop plants.

\section{MATERIALS AND METHODS}

\section{Bacterial strains and growth conditions.}

Three strains were used in this study: i) A. brasilense Sp245 wt, a bacterium isolated from surface-sterilized wheat roots (Brazil) (Baldani et al. 1986); ii) A. brasilense Faj009 (originally called Sp245a) (Costacurta et al. 1994), an isogenic mutant of Sp245 with a Tn5 insertion in the ipdC gene which codifies for indole-3-pyruvate decarboxylase, the main enzyme for IAA synthesis in A. brasilense, and with a $90 \%$ reduction of the wt IAA level (Dobbelaere et al. 1999); and iii) A. brasilense Faj164, a knockout mutant of Sp245 with a Tn5 insertion in the napA gene, which codifies the periplasmic nitrate reductase (Steenhoudt et al. 2001a). 
For NO quantification assays, bacteria were grown on ACR (Rodriguez-Cáceres 1982) during 4 days, transferred to liquid $\mathrm{OAB}$ medium (Okon et al. 1977) containing $10 \mathrm{mM} \mathrm{KNO}_{3}$ or $10 \mathrm{mM} \mathrm{NH}_{4} \mathrm{Cl}$ as $\mathrm{N}$ source, and incubated for $11 \mathrm{~h}$ (exponential) or $16 \mathrm{~h}$ (end of $\log$ phase) at $30^{\circ} \mathrm{C}$ with orbital agitation (100 rpm). Cells were harvested by centrifugation at $8,100 \times g$ for $10 \mathrm{~min}$ at $4^{\circ} \mathrm{C}$ and frozen in liquid nitrogen until they were processed. In these assays, $15 \mathrm{mM}$ L-arginine (Fluka) was added to the $\mathrm{NH}_{4}{ }^{+}$-containing $\mathrm{OAB}$ medium when indicated. For inoculation assays, bacteria were grown on ACR during 4 days, transferred to liquid medium containing $10 \mathrm{mM} \mathrm{NH}_{4} \mathrm{Cl}$, and incubated for $16 \mathrm{~h}$ as indicated above, after which cells were harvested by centrifugation. Inoculum was prepared by resuspending the bacterial pellet in SDW to a final concentration of $10^{9}$ cells $\mathrm{ml}^{-1}$. Inoculation doses were adjusted to $10^{7}$ cells seed $^{-1}$, an optimal concentration to achieve $A$. brasilense effects on tomato (Creus et al. 2005). Kanamycin at $25 \mu \mathrm{g} \mathrm{ml}^{-1}$ was added to the different media for Faj009 and Faj164 mutants.

To assess bacterial growth, optical density was measured at $540 \mathrm{~nm}$, and the MPN ml $\mathrm{m}^{-1}$ of culture was estimated in semisolid NFb medium (Döbereiner and Day 1976) according to Postgate (1969). To evaluate the effect of the NO scavenger cPTIO (Molecular Probes, Eugene, OR, U.S.A.) on the growth of $A$. brasilense, overnight cultures of bacteria grown in $\mathrm{OAB}$ medium were pelleted, resuspended in sterile phosphate buffer ( $\mathrm{pH} 7)$, and plated on LB agar or ACR. Filter disks imbibed in $1 \mathrm{mM}$ cPTIO, kanamycin at $25 \mu \mathrm{g} \mathrm{ml}^{-1}$, ethanol, or OAB medium were placed in the center of the bacteria lawn and plates were incubated for $24 \mathrm{~h}(\mathrm{LB})$ or $48 \mathrm{~h}(\mathrm{ACR})$ at $30^{\circ} \mathrm{C}$. Kanamycin (for wt) or ethanol (for Faj009 and Faj164) and OAB medium were used as positive and negative controls, respectively. The absence of a growth-inhibition zone around the filter disk was considered as indicative of no toxic effects.

\section{Quantification of NO in A. brasilense.}

NO production by $A$. brasilense was quantified by EPR (Komarov and Lai 1995). Cells were harvested by centrifugation after 11 or $16 \mathrm{~h}$ of growth and bacterial pellets were frozen in liquid nitrogen until they were processed. A spin trap solution of $10 \mathrm{mM}$ sodium $\mathrm{N}$-methyl-d-glucamine dithiocarbamate (MGD) in $1 \mathrm{mM} \mathrm{FeSO}_{4}$ was added to the frozen pellet. For measurements, defrost samples were transferred to bottomsealed Pasteur pipettes. The spectra were recorded at room temperature $\left(18^{\circ} \mathrm{C}\right)$ in a Bruker ECS 106 EPR spectrometer, operating at $9.5 \mathrm{Ghz}$. Instrument settings include $200 \mathrm{G}$, field scan; 83.886 s, sweep time; 327.68 ms, time constant; 5.983 $\mathrm{G}$, modulation amplitude; $50 \mathrm{kHz}$, modulation frequency; and $20 \mathrm{~mW}$, microwave power. Quantification of the spin adduct was performed using an aqueous solution of 4-hydroxy2,2,6,6-tetramethyl piperidine 1-oxyl (TEMPOL). TEMPOL is a stable free radical used as standard to obtain the concentration of other free radical adducts. The three lines of EPR spectra were integrated to obtain the area intensity, then the concentration of the spin adduct was calculated according to Kotake and associates (1996).

Measurements of NO production kinetics in the different media were done by monitoring changes in the intensity of the NO-specific fluorescent probe DAF-2DA (Calbiochem, La Jolla, CA, U.S.A.) (Kojima et al. 1998). Cultures (100 $\mu \mathrm{l})$ of A. brasilense wt and mutants grown for $16 \mathrm{~h}$ in $\mathrm{OAB}$ liquid medium (with $10 \mathrm{mM} \mathrm{NH}_{4} \mathrm{Cl}$, with or without $15 \mathrm{mM} \mathrm{L}$-arginine, or $10 \mathrm{mM} \mathrm{NO} 3 \mathrm{~K}$ ) were incubated at room temperature (approximately $20^{\circ} \mathrm{C}$ ) in an agitated 96-well plate containing $10 \mu \mathrm{M}$ DAF-2 DA. Measurements of NO production kinetics induced by hydroxylamine were obtained by adding $0.1 \mathrm{mM}$ $\mathrm{NH}_{2} \mathrm{OH} \cdot \mathrm{HCl}$ (Mallincrockdt, St. Louis) to the cultures grown in $\mathrm{NH}_{4}{ }^{+}$-containing $\mathrm{OAB}$ medium. Noninoculated media were used as controls. Fluorescence intensity was measured every 4 min for $2 \mathrm{~h}$ with a Fluoroskan Ascent microplate reader (480$\mathrm{nm}$ excitation, 525-nm emission; Labsystems, Ramsey, MN, U.S.A.).

\section{Seedling growth and root quantification.}

Seed of tomato (Solanum lycopersicum Mill. cv. ACE 55, commercially acquired) were surface sterilized in $3 \%$ ( $\mathrm{vol} / \mathrm{vol})$ sodium hypochlorite for $3 \mathrm{~min}$, rinsed several times in SDW, and germinated in darkness on moistened filter paper. Seedlings with radicles 1 to $2 \mathrm{~mm}$ long were selected and soaked for $3 \mathrm{~h}$ in the inoculum $\left(10^{7}\right.$ cells seed $\left.{ }^{-1}\right)$ or in SDW (noninoculated control), then were transferred to petri dishes with filter paper moistened with SDW, 5 or $10 \mathrm{mM} \mathrm{KNO}_{3}$, or 0.5 $\mathrm{mM} \mathrm{KNO}_{2}$, and incubated in a growth chamber at $25^{\circ} \mathrm{C}$ with a 14- and 10-h (light and dark, respectively) photoperiod, with $300 \mu \mathrm{mol}$ photon $\mathrm{m}^{-2} \mathrm{~s}^{-1}$. cPTIO $(1 \mathrm{~mm})$ was used as a NO scavenger to prevent NO-mediated effects. After 6 days of treatment, the number of lateral roots (of at least $1 \mathrm{~mm}$ in length) per seedling was counted and the length of primary roots was measured with a ruler. Also, the percentage of plants with a least one AR was calculated.

\section{Bacterial colonization assessment.}

Root material was weighed and homogenized in a mortar with sterile phosphate buffer $(\mathrm{pH} 7)$. Three 0.1-ml replicates from 1:10 serial dilutions were cultured in semisolid $\mathrm{NFb}$ medium (Döbereiner and Day 1976), and MPN of bacteria were estimated according to Postgate (1969). DW was measured by drying root samples in paper bags in an oven at $60^{\circ} \mathrm{C}$. Then, MPN of bacteria $\mathrm{g}^{-1}$ of root DW was calculated.

\section{Experimental design and statistical analysis of data.}

Growth kinetic experiments were done with three independent cultures for each treatment. In inoculation experiments, between 3 and 12 petri dishes per treatment, with 10 seeds each, were analyzed. NO quantifications by EPR were duplicated in pools of two (for $16 \mathrm{~h}$ ) or four (for $11 \mathrm{~h}$ ) pellets. Fluorometric determinations of NO were done in triplicate. Determinations of MPN of bacteria were done four times for each treatment. Values are expressed as means \pm standard error. Mean comparisons were done using Tukey's test $(P<0.05)$.

\section{ACKNOWLEDGMENTS}

We thank J. Vanderleyden for his generous supply of Faj009 and Faj164 strains and S. A. Larraburu for her technical assistance at the lab. C. Molina-Favero is a fellow from ANPCyT. This work was supported by Agencia Nacional de Promoción Científica y Tecnológica (ANPCyT, PICT 1-9767/00, and PICT 14457/03 to L. Lamattina and PICT 1-11187 to S. Puntarulo) and institutional grants from Universidad Nacional de Mar del Plata (UNMdP, AGR 195/05 to C. M. Creus) and Universidad de Buenos Aires (UBA), Argentina.

\section{LITERATURE CITED}

Baldani, V. L. D., Alvarez, U. A. B., Baldani, J. I., and Döbereiner, J. 1986. Establishment of inoculated Azospirillum spp. in the rhizosphere and in roots of field grown wheat and sorghum. Plant Soil 90:35-46.

Barbieri, R., and Galli, E. 1993. Effect on wheat root development of inoculation with an Azospirillum brasilense mutant with altered indole-3acetic acid production. Res. Microbiol. 144:69-75.

Barraud, N., Hassett, D. J., Hwang, S. H., Rice, S. A., Kjelleberg, S., and Webb, J. S. 2006. Involvement of nitric oxide in biofilm dispersal of Pseudomonas aeruginosa. J. Bacteriol. 188:7344-7353.

Bashan, Y., and Levanony, H. 1990. Current status of Azospirillum inoculation technology: Azospirillum as a challenge for agriculture. Can. J. Microbiol. 36:591-608.

Bashan, Y., Harrison, S. K., and Whitmoyer, R. E. 1990. Enhanced growth 
of wheat and soybean plants inoculated with Azospirillum brasilense is not necessarily due to general enhancement of mineral uptake. Appl. Environ. Microbiol. 56:769-775.

Bashan, Y., Alcaraz-Melendez, L., and Toledo, G. 1992. Responses of soybean and cowpea root membranes to inoculation with Azospirillum brasilense. Symbiosis 13:217-228.

Bashan, Y., Holguin, G., and de-Bashan, L. E. 2004. Azospirillum-plant relationships: Physiological, molecular, agricultural, and environmental advances (1997-2003). Can. J. Microbiol. 50:521-577.

Beligni, M. V., and Lamattina, L. 2001. Nitric oxide: A non-traditional regulator of plant growth. Trends Plant Sci. 6:508-509.

Boddey, R. M., Baldani, V. L. D., Baldani, J. I., and Döbereiner, J. 1986. Effect of inoculation of Azospirillum spp. on nitrogen accumulation by field grown wheat. Plant Soil 95:109-121.

Bothe, H., Körsgen, H., Lehmacher, T., and Hundeshagen, B. 1992. Differential effects of Azospirillum, auxin and combined nitrogen on the growth of the roots of wheat. Symbiosis 13:167-179.

Cao, Z. Y., Xuan, W., Liu, Z. Y., Li, X. N., Zhao, N., Xu, P., Wang, Z., Guan, R. Z., and Shen, W. B. 2007. Carbon monoxide promotes lateral root formation in rapeseed. J. Integr. Plant Biol. 49:1070-1079.

Casanovas, E. M., Barassi, C. A., Andrade, F. H., and Sueldo, R. J. 2003 Azospirillum-inoculated maize plant responses to irrigation restraints imposed during flowering. Cereal Res. Commun. 31:395-402.

Casimiro, I., Beeckman, T., Grahan, N., Bhalerao, R., Zhang, H., Casero, P., Sandberg, G., and Bennett, M. J. 2003. Dissecting Arabidopsis lateral root development. Trends Plant Sci. 8:165-171.

Cassán, F., Bottini, R., Schneider, G., and Piccoli, P. 2001. Azospirillum brasilense and Azospirillum lipoferum hydrolyze conjugates of GA20 and metabolize the resultant aglycones to GA1 in seedlings of rice dwarf mutants. Plant Physiol. 125:2053-2058.

Choi, P. S., Naal, Z., Moore, C., Casado-Rivera, E., Abruna, H. D., Helmann, J. D., and Shapleigh, J. P. 2006. Assessing the impact of denitrifier-produced nitric oxide on other bacteria. Appl. Environ. Microbiol. 72:2200-2205.

Cohen, E., Okon, Y., Kigel, J., Nur, I., and Henis, Y. 1980. Increase in dry weight and total nitrogen content in Zea mays and Setaria italica associated with nitrogen-fixing Azospirillum spp. Plant Physiol. 66:746-749.

Cohen, M. F., and Yamasaki, H. 2003. Involvement of nitric oxide synthase in sucrose-enhanced hydrogen peroxide tolerance of Rhodococcus sp. strain APG1, a plant-colonizing bacterium. Nitric Oxide 9:1-9.

Correa-Aragunde, N., Graziano, M., and Lamattina, L. 2004. Nitric oxide plays a central role in determining lateral root development in tomato. Planta 218:900-905.

Correa-Aragunde, N., Graziano, M., Chevalier, C., and Lamattina, L. 2006. Nitric oxide modulates the expression of cell cycle regulatory genes during lateral root formation in tomato. J. Exp. Bot. 57:581-588.

Costacurta, A., Keijers, V., and Vanderleyden, J. 1994. Molecular cloning and sequence analysis of an Azospirillum brasilense indole-3-acetic pyruvate decarboxylase gene. Mol. Gen. Genet. 243:463-472.

Creus, C. M., Sueldo, R. J., and Barassi, C. A. 2004. Water relations and yield in Azospirillum-inoculated wheat exposed to drought in the field. Can. J. Bot. 82:273-281.

Creus, M. C., Graziano, M., Casanovas, E. M., Pereyra, M. A., Simontacchi, M., Puntarulo, S., Barassi, C. A., and Lamattina, L. 2005. Nitric oxide is involved in the Azospirillum brasilense-induced lateral root formation in tomato. Planta 221:297-303.

Daniel, R. M., Smith, I. M., Philipp, J. A. D., Ratcliffe, H. D., Drozd, J. W., and Bull, A. T. 1980. Anaerobic growth and denitrification by Rhizobium japonicum and other rhizobia. J. Gen. Microbiol. 120:517521.

Dobbelaere, S., Croonenborghs, A., Thys, A., Vande Brooke, A., and Vanderleyden, J. 1999. Phytostimulatory effect of Azospirillum brasilense wild type and mutant strains altered in IAA production on wheat. Plant Soil 212:155-164.

Dobbelaere, S., Vanderleyden, J., and Okon, Y. 2003. Plant growth-promoting effects of diazotrophs in the rhizosphere. Crit. Rev. Plant Sci. 22:107-149.

Döbereiner, J., and Day, L. 1976. Associative symbiosis in tropical grasses: Characterization of microorganisms and dinitrogen fixing sites. Pages 518-538 in: Proc. 1st Int. Symp. $\mathrm{N}_{2}$ Fixation. W. E. Newton and C. J. Nyman, eds. Washington State University Press, Pullman.

Fallik, E., Sarig, S., and Okon, Y. 1994. Morphology and physiology of plant roots associated with Azospirillum. Pages 77-86 in: Azospirillum/Plant Associations. Y. Okon, ed. CRC Press, Boca Raton, FL, U.S.A.

Frey, A. D., and Kallio, P. T. 2003. Bacterial hemoglobins and flavohemoglobins: Versatile proteins and their impact on microbiology and biotechnology. FEMS (Fed. Eur. Microbiol. Soc.) Microbiol. Rev. 27:525545.

Gouvêa, C. M. C. P., Souza, J. F., Magalhaês, C. A. N., and Martins, I. S.
1997. NO-releasing substances that induce growth elongation in maize root segments. J. Plant Growth Regul. 21:183-187.

Hadas, R., and Okon, Y. 1987. Effect of Azospirillum brasilense inoculation on root morphology and respiration in tomato seedlings. Biol. Fertil. Soils 5:241-247.

Harari, A., Kigel, J., and Okon, Y. 1989. Involvement of IAA in the interaction between Azospirillum brasilense and Panicum miliaceum roots. Plant Soil 110:227-234.

Hartmann, A., and Zimmer, W. 1994. Physiology of Azospirillum. Pages 15-39 in: Azospirillum/Plant Association. Y. Okon, ed. CRC Press, Boca Raton, FL, U.S.A.

Huang, A. X., She, X. P., Huang, C., and Song, T. S. 2007. The dynamic distribution of $\mathrm{NO}$ and NADPH-diaphorase activity during IBAinduced adventitious root formation. Physiol. Plant. 130:240-249.

Jain, D. K., and Patriquin, D. G. 1985. Root hair deformation, bacterial attachment, and plant growth in wheat-Azospirillum associations. Appl. Environ. Microbiol. 48:1208-1213.

Jasid, S., Simontacchi, M., Bartoli, C. G., and Puntarulo, S. 2006. Chloroplasts as a nitric oxide cellular source. Effect of reactive nitrogen species on chloroplastic lipids and proteins. Plant Physiol. 142:1246-1255.

Jetten, M. S. M., Logemann, S., Muyzer, G., Robertson, L. A., de Vries, S., van Loosdrecht, M. C. M., and Kuenen, J. G. 1997. Novel principles in the microbial conversion of nitrogen compounds. Antonie Leeuwenhoek 71:75-93

Kapulnik, Y., Okon, Y., and Henis, Y. 1985. Changes in root morphology of wheat caused by Azospirillum inoculation. Can. J. Microbiol. 31:881-887.

Kojima, H., Nakatsubo, N., Kikuchi, K., Kawahara, S., Kirino, Y., Nagoshi, H., Hirata, Y., and Nagano, T. 1998. Detection and imaging of nitric oxide with novel fluorescent indicators: Diaminofluoresceins. Ann. Chem. 70:2446-2453.

Kolb, W., and Martin, P. 1985. Response of plant roots to inoculation with Azospirillum brasilense and to application of indolacetic acid. Pages 215-221 in: Azospirillum III: Genetics, Physiology and Ecology. W. Klingmuller, ed. Springer Verlag, Berlin.

Komarov, A. M., and Lai, C. S. 1995. Detection of nitric oxide production in mice by spin trapping electron paramagnetic resonance spectroscopy. Biochim. Biophys. Acta 1272:29-36.

Kotake, Y., Tanigawa, T., Tanigawa, M., Ueno, I., Allen, D. R., and Lai, C. S. 1996. Continuous monitoring of cellular nitric oxide generation by spin trapping with an iron-dithiocarbamate complex. Biochim. Biophys. Acta 1289:362-268.

Lamattina, L., and Polacco, J. 2007. Nitric oxide in plant growth, development and stress physiology. Plant Cell Monographs. Springer-Verlag GmbH \& Co. KG., Berlin and Heidelberg, Germany.

Lamattina, L., García-Mata, C., Graziano, M., and Pagnussat, G. 2003. Nitric oxide: The versatility of an extensive signal molecule. Annu. Rev. Plant Biol. 54:109-136.

Lombardo, M. C., Graziano, M., Polacco, J. C., and Lamattina, L. 2006. Nitric oxide functions as a positive regulator of root hair development. Plant Signal. Behav. 1:28-33.

Mantelin, S., and Touraine, B. 2004. Plant growth-promoting bacteria and nitrate availability: Impacts on root development and nitrate uptake. J. Exp. Bot. 55:27-34.

Modolo, L. V., Augusto, O., Almeida, I. M., Magalhaes, J. R., and Salgado, I. 2005. Nitrite as the major source of nitric oxide production by Arabidopsis thaliana in response to Pseudomonas syringae. FEBS (Fed. Eur. Biochem. Soc.) Lett. 579:3814-3820.

Molina-Favero, C., Creus, C. M., Lanteri, M. L., Correa-Aragunde, N., Lombardo, M. C., Barassi, C. A., and Lamattina, L. 2007. Nitric oxide and plant growth promoting rhizobacteria: Common features influencing root growth and development. Adv. Bot. Res. 46:1-33.

Okon, Y., and Kapulnik, Y. 1986. Development and function of Azospirillum-inoculated roots. Plant Soil 90:3-16.

Okon, Y., and Labandera-González, C. A. 1994. Agronomic applications of Azospirillum: An evaluation of 20 years worldwide field inoculation. Soil Biol. Biochem. 26:1551-1601

Okon, Y., Albrecht, S. L., and Burris, H. 1977. Methods for growing Spirillum lipoferum and for counting it in pure culture and in association with plants. Appl. Environ. Microbiol. 33:85-88.

Ona, O., Van Impe, J., Prinsen, E., and Vanderleyden, J. 2005. Growth and indole-3-acetic acid biosynthesis of Azospirillum brasilense Sp245 is environmentally controlled. FEMS (Fed. Eur. Microbiol. Soc.) Microbiol. Lett. 246:125-132.

Ötvös, K., Pasternak, T. P., Miskolczi, P., Domoki, M., Dorjgotov, D., Szücs, A., Bottka, S., Dudits, D., and Fehér, A. 2005. Nitric oxide is required for, and promotes auxin-mediated activation of, cell division and embryogenic cell formation but does not influence cell cycle progression in alfalfa cell cultures. Plant J. 43:849-860.

Pagnussat, G. C., Simontacchi, M., Puntarulo, S., and Lamattina, L. 2002. 
Nitric oxide is required for root organogenesis. Plant Physiol. 129:954956

Pagnussat, G. C., Lanteri, M. L., and Lamattina, L. 2003. Nitric oxide and cyclic GMP are messengers in the indole acetic acid-induced adventitious rooting process. Plant Physiol. 132:1241-1248.

Postgate, J. R. 1969. Viable counts and viability. Pages 611-628 in: Methods in Microbiology. J. R. Norris and D. W. Ribbons, eds. Academic Press, New York.

Pothier, J. F., Wisniewski-Dyé, F., Weiss-Gayet, M., Moënne-Loccoz, Y., and Prigent-Combaret, C. 2007. Promoter-trap identification of wheat seed extract-induced genes in the plant-growth-promoting rhizobacterium Azospirillum brasilense Sp245. Microbiology 153:3608-3622.

Rodríguez-Cáceres, E. A. 1982. Improved medium for isolation of Azospirillum spp. Appl. Environ. Microbiol. 44:990-991.

Saubidet, M. I., Fatta. N., and Barneix. A. J. 2002. The effect of inoculation with Azospirillum brasilense on growth and nitrogen utilization by wheat plants. Plant Soil 245:215-222.

Spaepen, S., Vanderleyden, J., and Remans, R. 2007. Indole-3-acetic acid in microbial and microorganism-plant signaling. FEMS (Fed. Eur. Microbiol. Soc.) Microbiol. Rev. 31:425-448.

Steenhoudt, O., Keijers, V., Okon, Y., and Vanderleyden, J. 2001a. Identification and characterization of a periplasmic nitrate reductase in Azospirillum brasilense Sp245. Arch. Microbiol. 175:344-352.

Steenhoudt, O., Ping, Z., Vande Broek, A., and Vanderleyden, J. 2001b. A spontaneous chlorate-resistant mutant of Azospirillum brasilense Sp245 displays defects in nitrate reduction and plant root colonization. Biol. Fertil. Soils 33:317-322.

Stuehr, D. J. 1997. Structure-function aspects in the nitric oxide synthases. Annu. Rev. Pharmacol. Toxicol. 37:339-359.

Tewari, R. K., Hahn, E. J., and Paek, K. Y. 2007. Function of nitric oxide and superoxide anion in the adventitious root development and antioxidant defence in Panax ginseng. Plant Cell Rep. 27:563-573.

Thippeswamy, T., McKay, J. S., Quinn, J. P., and Morris, R. 2006. Nitric oxide, a biological double-faced janus-is this good or bad? Histol. Histopathol. 21:445-458.
Tien, T. M., Gaskins, M. H., and Hubbell, D. H. 1979. Plant growth substances produced by Azospirillum brasilense and their effect on the growth of pearl millet (Pennisetum americanum L.). Appl. Environ. Microbiol. 37:1016-1024.

Weitzberg, E., and Lundberg, J. O. N. 1998. Nonenzymatic nitric oxide production in humans. Nitric Oxide 2:1-7.

Wrage, N., Velthof, G. L., van Beusichem, M. L., and Oenema, O. 2001. Role of nitrifier denitrification in the production of nitrous oxide. Soil Biol. Biochem. 33:1723-1732.

Yahalom, E., Okon, Y., and Dovrat, A. 1990. Possible mode of action of Azospirillum brasilense strain $\mathrm{Cd}$ on the root morphology and nodule formation in burr medic (Medicago polymorpha). Can. J. Microbiol. 36:10-14.

Zakharova, E. A., Shcherbakov, A. A., Brudnik, V. V., Skripko, N. G., Bulkhin, N. S., and Ignatov, V. V. 1999. Biosynthesis of indole-3-acetic acid in Azospirillum brasilense: Insights from quantum chemistry. Eur. J. Biochem. 259:572-576.

Zeidler, D., Zahringer, U., Gerber, I., Dubery, I., Hartung, T., Bors, W. Hutzler, P., and Durner, J. 2004. Innate immunity in Arabidopsis thaliana: Lipopolysaccharides activate nitric oxide synthase (NOS) and induce defense genes. Proc. Natl. Acad. Sci. U.S.A. 101:1581115816.

Zemojtel, T., Frohlich, A., Palmieri, M. C., Kolanczyk, M., Mikula, I. Wyrwicz, L. S., Wanker, E. E., Mundlos, S., Vingron, M., Martasek, P, and Durner, J. 2006. Plant nitric oxide synthase: A never-ending story? Trends Plant Sci. 11:524-525.

Zhang, H., and Forde, B.G. 2000. Regulation of Arabidopsis root development by nitrate availability. J. Exp. Bot. 51:51-59.

Zimmer, W., and Bothe, H. 1988. The phytohormonal interactions between Azospirillum and wheat. Plant Soil 110:239-247.

Zimmer, W., Penteado-Stephan, M., and Bothe, H. 1984. Denitrification by Azospirillum brasilense Sp 7. Arch. Microbiol. 138:206-211.

Zimmer, W., Roeben, K., and Bothe, H. 1988. An alternative explanation for plant growth promotion by bacteria of the genus Azospirillum. Planta 176:333-342. 